\title{
Recruiting families for an intervention study to prevent second-hand smoke exposure in children
}

\author{
Sasha G. Hutchinson ${ }^{1}$, Constant P. van Schayck ${ }^{2}$, Jean W. M. Muris ${ }^{2}$, Frans J. M. Feron ${ }^{3}$ and Edward Dompeling ${ }^{\text {* }^{*}}$ (D)
}

\begin{abstract}
Background: We evaluated the effectiveness of different recruitment strategies used in a study aimed at eliminating/ reducing second-hand smoke (SHS) exposure in Dutch children 0-13 years of age with a high risk of asthma.

Methods: The different strategies include: 1) questionnaires distributed via home addresses, physicians or schools of the children; 2) cohorts from other paediatric studies; 3) physicians working in the paediatric field (family physicians, paediatricians and Youth Health Care (YHC) physicians); and 4) advertisements in a local newsletter, at child-care facilities, and day-care centres.
\end{abstract}

Results: More than 42,782 families were approached to take part in the screening of which 3663 could be assessed for eligibility. Of these responders, 196 families met the inclusion criteria for the study. However, only 58 (one third) could be randomised in the trial, mainly because of no interest or time of the parents. The results showed that recruiting families who expose their children to SHS exposure is very challenging, which may be explained by lack of 'recognition' or awareness that SHS occurs in homes. The presence of asthma in the family, respiratory symptoms in the children, and even incentives did not increase parental motivation for participation in the study.

Conclusions: The recruitment process for an intervention program addressing SHS exposure in children was considerably more challenging and time consuming than anticipated. Barriers at both a parents level and a doctor's level can be discriminated.

Keywords: Hard-to-reach populations, Second-hand smoke, Children, Recruitment

\section{Background}

Second-hand smoke (SHS) exposure in children is still a problem of major societal concern. The WHO estimates that about $40 \%$ of children worldwide are exposed [1]. SHS exposure in Dutch children may have decreased over the past years but not in families of low social economic groups [2]. The adverse health effects in terms of associated morbidity and mortality of SHS exposure in children are large [3], including increased risk of sudden infant death syndrome, respiratory tract infections and complaints, asthma, and even meningitis in children [4-7]. Therefore, effective strategies are urgently needed to prevent SHS exposure in children [8]. We developed

\footnotetext{
* Correspondence: edward.dompeling@mumc.nl

${ }^{1}$ Department of Paediatric Respiratory Medicine, Maastricht University

Medical Centre (MUMC+) / CAPHRI School for Public Health and Primary

Care, P.O. Box 616, 6200, MD, Maastricht, the Netherlands

Full list of author information is available at the end of the article
}

a motivational interviewing intervention with feedback of the children's urine cotinine level to prevent SHS exposure in children with a high risk of asthma (the PREPASE study [9]). The purpose of the PREPASE study was to test the effectiveness of the intervention program in a randomized controlled trial (RCT) with approximately 150 families with children $0-13$ years of age with a high risk of asthma (due to asthma in a biological parent and/or sibling) and SHS exposure at home.

The aims of this study were: 1) to describe and evaluate the different recruitment strategies of the PREPASE study; 2) to assess the influence of socioeconomic factors, presence of asthma in the family, and respiratory symptoms in the children on the effectiveness of the recruitment process.

(c) The Author(s). 2018 Open Access This article is distributed under the terms of the Creative Commons Attribution 4.0 International License (http://creativecommons.org/licenses/by/4.0/), which permits unrestricted use, distribution, and reproduction in any medium, provided you give appropriate credit to the original author(s) and the source, provide a link to the Creative Commons license, and indicate if changes were made. The Creative Commons Public Domain Dedication waiver (http://creativecommons.org/publicdomain/zero/1.0/) applies to the data made available in this article, unless otherwise stated. 


\section{Methods}

The study protocol and recruitment strategies for the PREPASE study were previously described [9]. The recruitment strategies are summarized in Fig. 1.

\section{Population-based strategies}

Survey among 6,987 families with children aged 0-13 years Our initial strategy was to select eligible candidates for the PREPASE study via a survey. The civil affairs departments of three communities (Heerlen, Maastricht and Sittard-Geleen) in South-Limburg, Netherlands, provided 22,532 addresses where children within the age range of $0-13$ years were living. We randomly selected 6,987 of those addresses and sent a package including an invitation letter to participate in the study, an informed consent form, two questionnaires (responder (A) and non-responder (B), see Additional file 1) and a return envelope. Parents were informed that participation was voluntary, and that every 50th participant would receive a gift voucher of $€ 25$. Non-responders would receive a single reminder letter after two weeks. Parents who wanted to participate could complete a questionnaire A consisting of 91 items including; family characteristics (nine questions), the child's general and respiratory health (including the ISAAC questionnaire [8], 38 questions), parental smoking behaviour and SHS exposure to the child (44 questions of which 36 were double questions 18 for the primary responder and 18 for their possible partner). Parents who were not willing to participate with the survey were asked if they could complete questionnaire B (11 items, including gender and birth date of the child, relationship of the caregiver(s) to the child, wheezing and respiratory complaints in the past 12 months, SHS exposure and reasons for nonparticipation) for the purpose of a nonresponder analysis. Parents could give permission to be contacted for a possible follow-up study via the informed consent form. Eligible families who gave permission were telephoned and provided with information about the RCT. Interested parents received an information letter of three pages describing the aim of the study (to test the effectiveness of a program to prevent SHS in children), study duration, measurements, pros (gaining more knowledge of the respiratory health of their child) and cons (time investment) of participation, protection of their data, incentive of $€ 100$ for complete participation, and a gift for the child after every lung function measurement, and further instructions. The letter also included an informed consent form and return envelope.

\section{Participants from other paediatric studies}

Participants were selected from the MIKADO [10] and the ADEM study [11] from the department of paediatric respiratory medicine Maastricht University Medical

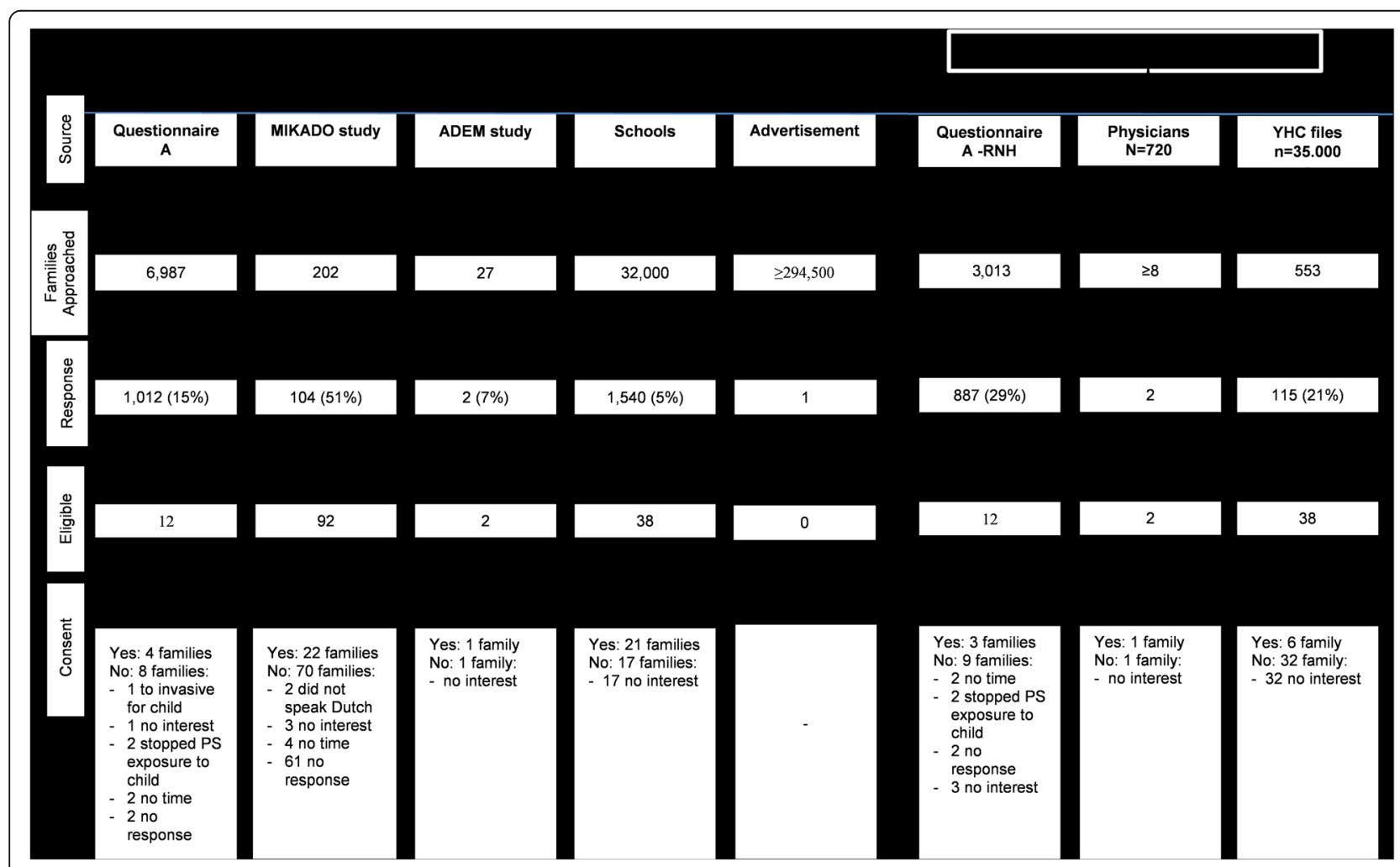

Fig. 1 Flowchart recruitment and enrolment 
Centre (MUMC+). The MIKADO study was recruiting families during the same time as the PREPASE study, by means of an electronic survey (64 items) about obesity and asthma among 40,000 families with children 616 years of age living in South-Limburg. Families that were not eligible for the MIKADO study or who completed the ADEM study, and in both cases were eligible to participate in the PREPASE study and gave permission to be contacted for possible follow-up studies, received hardcopy information concerning the PREPASE intervention study as mentioned above. Parental willingness for participation was assessed two weeks later by phone. Parents who wanted to participate received an informed consent form and return envelope and were randomised in the study.

\section{Schools}

Parents of 32,000 children aged 6-12 years received an invitation letter to participate in an electronic survey study (see Additional file 1) through the primary school of their child. Recruitment on primary schools in the Netherlands was feasible in a similar study [12]. The 9 main school organizations in South-Limburg were informed about the aims of the PREPASE study and asked for permission to contact their schools. Seven organisations gave permission. First, 205 schools were informed about the study via e-mail and were telephoned one week later to ask for their participation. Sixty-four per cent $(n=132)$ agreed to distribute letters to the children of their schools. The letters were personally delivered to the schools by a member of our research team. All children received a letter addressed to their parents asking them to participate in an electronic survey about the respiratory health of children living in South-Limburg. Each letter contained an original log-in name and password. To encourage participation, parents were informed that we would draw 50 amusement park tickets at the end of the study. The survey consisted of 44 items; general characteristics of the child and family (10 questions), the child's general and respiratory health (23 questions) and SHS exposure to the child (4 questions for the primary responder and 4 for their possible partner), and questions regarding participation in the followup study (3 questions). At the end of the questionnaire, brief information of the PREPASE study was given in 6 short sentences. Parents were informed that they were possibly eligible to participate in the PREPASE study in case they smoked in the presence of their child at home and the child had a first degree relative with asthma. Furthermore, parents also received information about our aim (to help us make a program to reduce SHS exposure in children at high risk for asthma), information on study duration and non-invasiveness of the measurement, and that the child would receive a gift after every measurement and families an incentive of $€ 200$ after complete participation in the trial. Additionally, parents were asked which strategy or intervention program they thought was better to educate parents about SHS exposure in children and how to prevent it. All parents received a reminder letter via the primary schools of their children after two weeks.

\section{Advertisements}

A single advertisement was placed in a local newsletter that is freely distributed to almost every house in SouthLimburg $(n=294,500)$ once per week. Additionally, advertisements were placed in most (444) child-care facilities and day-care centres in South-Limburg.

\section{Physician based strategies}

Survey among 3,013 families with children aged 0-13 years

The Registration Network of Family Practices (RNH Dutch acronym), uses a computerised database containing patient characteristics of 21 primary care physicians' group practices in Limburg, the Netherlands [13]. Nine out of the 21 primary care physicians' group practices of the $\mathrm{RNH}$ agreed to participate in the study. The main reason for not participating was lack of time. The participating physicians selected all children $0-13$ year of age from the RNH database $(n=3,013)$ and provided them with a personalised information package (the same information package as the 6,987 families mentioned above under population based strategy 1 and during the same time period. Non-responders received a reminder letter from their physicians after two weeks.

\section{Physicians working in the paediatric field}

All primary care physicians, paediatricians and youth health care (YHC) physicians $(n=720)$ in SouthLimburg were asked to select and invite eligible families to participate from their patient registries or actively during consultations (during the year 2011). The physicians were informed about the study in various ways to encourage their participation: via their newsletters and e-mail addresses, telephone calls to their practices and by giving oral presentations about the PREPASE study. To further encourage the primary care physicians, we agreed to give them an incentive of $€ 25$ per selected eligible family and additionally $€ 75$ for every family they personally invited for the study whom also chose to participate in the study.

\section{Patient registries}

Registries of 35,000 children in South-Limburg at the Regional Public Health Service department of YHC were checked for eligibility (child 0-13 years of age with high risk of asthma and SHS exposure at home). The YHC is a preventive health care for all children aged 0-19 years 
living in the Netherlands purposed to promote, protect and monitor the physical, psychological, social and cognitive development of children and advise parents and children about healthy development for the child [14]. In 2009, 93\% of all children aged 0-4 years were reached by the YHC [15]. Therefore, the YHC service is an opportune place to support recruitment of children in prevention studies. All available files were checked by two research assistants. Eligible families received an invitation letter from their physician to participate in the study. We also tried to contact the families by phone. The families were informed that the MUMC+ was doing a study about irritable substances and respiratory health in children. Families were asked to complete an answering form stating if they wanted to be contacted (yes or no) by a member of the research group for more information. Interested families were offered a lung function measurement and urine cotinine analysis of their children at home. During the measurement parents were informed about irritable substances that can cause respiratory complaint of children, one of which is SHS exposure in children. The parents were informed about the PREPASE study and asked if they wanted to participate.

\section{Data analysis}

Data were analysed using SPSS version 20 (SPSS INC., Chicago, Il, USA). The descriptive statistics of the recruitment strategies: questionnaire A, MIKADO and schools are presented. Data from $N=154$ children (obtained via questionnaire A, MIKADO and schools) who were eligible to participate in the RCT were combined to check for possible difference between the families who provided consent to participate in the study and those who did not. Chi-square tests and logistic regression analysis were used for the categorical variables and the independent $t$-test for the continuous variables. Additionally, parents' choice for the most effective strategy to educate parents about SHS exposure in children and how to prevent it was analysed with multinomial regression analysis.

\section{Results}

\section{Recruitment and enrolment}

A summary of the recruitment strategies is shown in Fig. 1:

1. Population based strategies: at least 39,216 families were approached (excluding the strategy approach via advertisements). The combined response rate was only $7 \%(n=2,667)$. The response rate from the MIKADO group was substantially higher than the other strategies probably because the families were approached by letter and a phone call. The telephone numbers of the participants of the other strategies were not available. Just $6 \%(n=151)$ of all the responders of the population based strategies were eligible to participate in the RCT and about one-third of those $(n=49 ; 32 \%)$ provided consent to be randomized in the study. The main reason for not participating in the RCT was due to lack of interest. Sixty per cent of the eligible families did not respond to our invitation letter and or phone calls. Furthermore, based on the selection of MIKADO data all participants were eligible for the PREPASE study. However, during the telephone contact 12 families were no longer eligible because the parent reported they had stopped smoking or had never smoked in the first place.

2. Physician based strategies: 720 physicians were asked to help recruit participants for the PREPASE study and 35,000 patient registries at the YHC department of the Regional Public Health Services in SouthLimburg were checked for eligibility. In total, at least 3,566 families were approached via the physician based strategies. The mean response rate was $28 \%$ $(n=1,010)$. In total, $7 \%(n=70)$ of all the responders were eligible to participate in the RCT. A few as 10\% $(\mathrm{n}=7)$ gave consent for the RCT. The main reason for not participating in the trial was no interest. The total amount of families approached via their physicians is unknown. One primary care physician communicated back with us about inviting two eligible families, two paediatricians provided contact information of five families that were interested, and one YHC physician provided information of one family that was interested to participate in the PREPASE study.

\section{Characteristics of the responders and non-responders}

The characteristics of the responders of questionnaire A, MIKADO and the electronic survey via the schools are provided in Table 1. Parental active smoking and SHS in children were rather similar in all four strategies, including the frequencies of the reported respiratory complaints in children. An interesting observation was that a relatively low amount of families reported to have low education. Furthermore, regarding questionnaire $\mathrm{A}$, the response rate of the group approached via physicians (29\%) was significantly $(p<0.01)$ higher compared to the group that randomly received the invitation package via their postal address (15\%). In total, $5 \%(n=508)$ of all the parents that were invited to complete questionnaire A (via communities as well as via physicians $(n=$ 10,000)) completed the non-responders questionnaire B. There were no differences between the responders of questionnaire $\mathrm{A}$ and questionnaire $\mathrm{B}$ with regards to the prevalence of SHS exposure in children, respiratory tract infections in the last 12 months, recent wheezing and asthma (results presented elsewhere [16]), which suggested no selection bias. About 60\% reported they did 
Table 1 Participants' characteristics per strategy

\begin{tabular}{|c|c|c|c|c|c|}
\hline Strategy & $\begin{array}{l}\text { Questionnaire A } \\
\text { communities } \\
n=6,987\end{array}$ & $\begin{array}{l}\text { Questionnaire A } \\
\text { physicians } \\
n=3,013\end{array}$ & $\begin{array}{l}\text { MIKADO } \\
n=202\end{array}$ & $\begin{array}{l}\text { Schools } \\
n=32,000\end{array}$ & $\begin{array}{l}\text { Total } \\
42,202\end{array}$ \\
\hline Response (n (\%)) & $1,012(15)$ & $887(29)$ & $104(51)$ & $1,540(5)$ & $3543(8)$ \\
\hline \multicolumn{6}{|l|}{ Primary caregiver responder: } \\
\hline - Mother (n (\%)) & $843(83)$ & 757 (85) & $87(84)$ & $1,244(81)$ & 2,931 (83) \\
\hline - Father (n (\%)) & $158(16)$ & $120(14)$ & $14(14)$ & $271(18)$ & $563(16)$ \\
\hline - Other (n (\%)) & $11(1)$ & $10(1)$ & $3(3)$ & $25(2)$ & $49(1)$ \\
\hline Age of children (mean (SD)) & $6.2(4.1)$ & $7.6(4.2)$ & $9.2(2.3)$ & $8.1(2.5)$ & $7.5(3.6)$ \\
\hline Age of mother (mean (SD)) & $38.9(6.3)$ & $40.3(5.6)$ & Not asked & $39.8(5.1)$ & $39.8(5.7)^{c}$ \\
\hline \multicolumn{6}{|l|}{ Highest parental education ${ }^{a}$} \\
\hline - Low (n (\%)) & $31(3)$ & $41(5)$ & $23(22)$ & $41(3)$ & $136(4)$ \\
\hline - Middle (n (\%)) & $268(27)$ & $262(30)$ & $50(48)$ & $405(29)$ & $985(28)$ \\
\hline - High (n (\%)) & $404(40)$ & $454(51)$ & $28(27)$ & $730(45)$ & $1,616(46)$ \\
\hline - Academic (n (\%)) & $300(30)$ & $126(14)$ & $3(3)$ & $332(22)$ & $761(21)$ \\
\hline - Other (n (\%)) & 0 & 0 & & $32(2)$ & $32(1)$ \\
\hline - Missing (n (\%)) & $9(1)$ & $4(1)$ & & & $13(0)$ \\
\hline Active smoking of both parents $(\mathrm{n}(\%))^{\mathrm{b}}$ & $306(16)$ & $257(15)$ & $141(70)$ & $507(17)$ & $1,211(34)$ \\
\hline Active smoking at least one parent per family (n (\%)) & $250(25)$ & $210(24)$ & $104(100)$ & $390(25)$ & $954(27)$ \\
\hline Smoking in the presence of the child $(n(\%))$ & $131(13)$ & $135(15)$ & $104(100)$ & $141(9)$ & $511(14)$ \\
\hline Wheezing ever (n (\%)) & $283(28)$ & $255(29)$ & $29(28)$ & $478(31)$ & $1,045(29)$ \\
\hline Wheezing in the past 12 months (n (\%)) & $144(14)$ & $114(13)$ & $7(7)$ & $229(15)$ & $494(14)$ \\
\hline Asthma diagnosis $(n(\%))^{c}$ & $66(13)$ & $65(12)$ & 0 & $161(11)$ & $292(8)$ \\
\hline Respiratory tract infection in the past 12 months ( $\mathrm{n}(\%)$ ) & $413(41)$ & $278(31)$ & Not asked & $567(37)$ & $1,258(37)^{c}$ \\
\hline Asthma in the first degree relative (n (\%)) & $258(26)$ & $215(24)$ & $104(100)$ & $423(28)$ & $1,000(28)$ \\
\hline
\end{tabular}

not complete questionnaire A because they did not allow smoking inside their homes, and 50\% because their children did not have respiratory complaints. Reasons such as no interest or lack of time were reported less frequently.

Regarding the electronic survey via schools, $42 \%$ ( $n=$ 649) of parents reported that they were willing to help the PREPASE study develop a program to stop SHS exposure in children. Twelve per cent $(n=76)$ of these parents also reported SHS exposure in their children at home. Among the parents that were not willing to help the PREPASE study, 78\% reported that they did not want to participate because they did not allow smoking in their homes and 54\% reported that their reason was because their child did not have respiratory complaints. No interest $(6 \%)$ or lack of time $(6 \%)$ was less frequently reported as reasons for not wanting to participate in the study. Furthermore, the parents were asked what strategy they would find more effective for preventing SHS in children (Table 2). In general, $44 \%$ of all parents found that SHS exposure in children could best be prevented by a motivational interviewing intervention program. Compared to parents not exposing their children, parents exposing their children to SHS were less inclined to indicate motivational interviewing and a group program in their neighbourhood as an effective strategy for prevention of SHS exposure. Almost, one third of the parents with SHS exposure in their children reported that an internet intervention program would be more effective. Last, data of 154 eligible participants were combined, see Table 3 . We found no difference between the group that participated and the group that did not participate in the RCT.

\section{Discussion}

We described the recruitment strategies of the PREPASE study. The recruitment process was considerably more challenging and time consuming than anticipated, and none of the strategies proved to be very effective. At least 42,782 families were asked to participate. Finally, 196 families met the inclusion criteria for the study but only 58 families 
Table 2 Parents' choice for most effective strategy to inform parents about passive smoking in children and how to prevent it

\begin{tabular}{|c|c|c|c|c|}
\hline \multirow[t]{2}{*}{ Strategy } & \multicolumn{2}{|c|}{ Smoking in the presence of the child } & \multirow[t]{2}{*}{ Total $(n=1,540)$} & \multirow[t]{2}{*}{ OR $(95 \% \mathrm{Cl})^{\mathrm{a}}$} \\
\hline & YES- $n=141(9)$ & NO- $n=1,399(91)$ & & \\
\hline An internet program (n (\%)) & $45(32)$ & $131(9)$ & $176(11)$ & $2.0(1.2-3.4)^{\#}$ \\
\hline A program via telephone contacts (n (\%)) & $3(2)$ & $11(1)$ & $14(1)$ & $1.6(0.4-6.1)$ \\
\hline $\begin{array}{l}\text { A program consisting of motivational interviewing } \\
\text { with a trained coach at home }(n(\%))\end{array}$ & $25(18)$ & $655(47)$ & $680(44)$ & $0.2(0.1-0.4)^{\#}$ \\
\hline $\begin{array}{l}\text { A group program for parents at a central location } \\
\text { in a neighbourhood }(\mathrm{n}(\%))\end{array}$ & $13(9)$ & $161(12)$ & $174(11)$ & $0.5(0.2-0.9)^{\#}$ \\
\hline $\begin{array}{l}\text { A combined program consisting of contacts by } \\
\text { phone and motivational interviewing at home (n (\%)) }\end{array}$ & $29(29)$ & $290(21)$ & $319(21)$ & $0.6(0.3-1.0)$ \\
\hline $\begin{array}{l}\text { Other }(\mathrm{n}(\%)) \\
\text { - Do not know }(60(34 \%)) \\
\text { - TV documentaries and confrontational } \\
\text { tv-advertisements }(29(16 \%)) \\
\text { - Stop active smoking }(21(12 \%)) \\
\text { - Smoking ban / take tobacco products of the } \\
\text { market }(18(10 \%)) \\
\text { - Education about smoking at schools }(12(7 \%)) \\
\text { - Direct confrontation during e.g. doctor visits (11 (6\%)) } \\
\text { - Combination of all programs }(9(5 \%)) \\
\text { - Increase taxes and prices of tobacco products (5 (3\%)) } \\
\text { - Make SHS exposure in children punishable by law (5 (3\%)) } \\
\text { - Increase health insurance of smokers (3 (2\%)) } \\
\text { - Tailored to personal needs and intervention } \\
\text { strategy (2 (1\%)) } \\
\text { - Free smoking-cessation programs or therapy (1 (1\%)) } \\
\text { - Nothing will help (1 (1\%)) }\end{array}$ & $26(19)$ & $151(11)$ & $177(12)$ & reference \\
\hline
\end{tabular}

a $\mathrm{OR}=$ Odds Ratio, $95 \% \mathrm{Cl}=95 \%$ Confidence Interval

${ }^{\#} p<0.05$

participated in the RCT. The observations suggest that we were dealing with at least two main areas of barriers arising from 1 ) the physicians and 2) the study population.

\section{Barrier 1: The physicians}

The current study showed that even physicians, who play a crucial role in the prevention of SHS exposure in children, were not actively engaged in the study. This is very disappointing, because prevention of SHS exposure in children can decrease morbidity and mortality in children considerably [3]. In previous studies from our department, recruitment of children for research by means of the RNH has shown to be more effective, likely due to the different nature of their research questions $[11,17]$. In the PREPASE study, only 9 out of $21 \mathrm{RNH}$ practices participated in the recruitment process. The

Table 3 Comparison between eligible participants $(n=154)$ who participated and who did not participate in the randomized controlled trial $(R C T)$

\begin{tabular}{|c|c|c|c|c|}
\hline & RCT $-Y E S n=50$ & RCT- NO $n=104$ & OR $(95 \% \mathrm{Cl})^{\mathrm{a}}$ & $p$-value \\
\hline Age of the child (mean (SD)) & $8.2(2.4)$ & $9.2(2.5)$ & & $p=0.97$ \\
\hline Wheezing ever (n (\%)) & $17(34)$ & $33(32)$ & $1.1(0.5-2.3)$ & $p=0.78$ \\
\hline Wheezing last 12 months (n (\%)) & $7(14)$ & $12(12)$ & - & $p=0.28$ \\
\hline \multicolumn{5}{|l|}{ SHS by": } \\
\hline Mother (n (\%)) & $23(46)$ & $31(30)$ & Reference & \\
\hline Father (n (\%)) & $12(24)$ & $36(35)$ & $2.2(1.0-5.2)$ & $p=0.06$ \\
\hline Both parents (n (\%)) & $15(30)$ & $36(35)$ & $1.8(0.8-4.0)$ & $p=0.16$ \\
\hline \multicolumn{5}{|l|}{ Highest parental education": } \\
\hline Low (n (\%)) & $9(18)$ & $14(13)$ & Reference & \\
\hline Middle (n (\%)) & $24(48)$ & $48(46)$ & $1.3(0.5-3.4)$ & $p=0.61$ \\
\hline High/Academic (n (\%)) & $16(32)$ & $41(39)$ & $1.7(0.6-4.6)$ & $p=0.34$ \\
\hline
\end{tabular}

a OR = Odds Ratio, $95 \% \mathrm{Cl}=95 \%$ Confidence Interval

\# Values may not add up due to missing values 
response rates for questionnaires A were significantly higher in the group that received an invitation via their physicians than an invitation of the project group, suggesting that parents might be more willing to participate when they are approached via their physicians instead of via other strategies [18]. A study evaluating the recruitment of participants via Dutch physicians found that recruitment was more successful when physicians were asked to recruit prevalent cases instead of incident cases, if physicians did not have to be alert during consultation, and when participants were invited by mail. In the PREPASE study, physicians were asked to recruit participants actively during consultations as well as retrospectively through the patient files [19]. But only 4 of 720 physicians reported back to the research group concerning possible participants. So, even the recruitment of "prevalent cases" was not effective. Possibly because not all physicians keep a good record of whether or not a child is exposed to SHS [20], making it difficult for them to identify the eligible families for the study via their patient registries or International Classification of Primary Care (ICPC) registration of nicotine abuses in $\mathrm{RNH}$ practices. Comparable recruitment problems in a primary care setting had been described in the recent REFRESH study, assessing the influence of an MI intervention combined with feedback about home air quality on SHS exposure in preschool children [21].

Additionally, in the case of YHC physicians, currently more of their tasks regarding screening and prevention of health problems in children are done by the YHC nurses. Therefore, the YHC nurses were also requested to help to recruit participants for the study, but they did not provide eligible participants either. Nevertheless, physicians working in child-care settings have a unique opportunity to counsel parents for SHS exposure in children but infrequently do so due to barriers such as lack of time, competing priorities and fear of negative parental response [22-24]. A study indicated that physicians are less likely to aid to smoking cessation in socially and economically deprived groups [25]. For instance, one primary care physician reported to our project team that he did not want to participate especially because the families that exposed their children to SHS were of low socioeconomic status, and he did not want to damage the doctor-patient relationship. Similarly, another physician did not want to participate because of the resistance he gets from patients when talking about exposure in children. Other physicians said that they were not able to participate because of lack of time or due to participation in other research. But the majority of physicians was not actively involved and did not provide reasons for non-participation.

\section{Barrier 2: The study population}

In general, the presence of asthma in the family or of respiratory symptoms in the children did not increase parental motivation for participation in the study, neither did the offering of incentives. At the time the PREPASE study started (2010), the Dutch ban on smoking in public places was already in effect. Although the reported prevalence of SHS in Dutch children decreased further since the smoking ban, a considerable amount of children were still exposed to SHS, especially in the group of low-social economic status and heavy smokers [2]. The media attention and social pressure since the smoking ban in public places might have motivated parents to participate in a study like PREPASE in order to receive support to stop SHS exposure in their children. In contrast, the media attention could have also made parents more reluctant to participate in the study due to perhaps feelings of guilt, shame or fear of being criticized. In our experience the last may have played a greater role. Stigmatisation of smokers is a well-known phenomenon in the literature [26]. Some parents reacted very aggressively towards our project team during the telephone contacts regarding SHS in children and others have reported in questionnaires that they were not smokers, yet the questionnaires had the odour of tobacco. Furthermore, the home was probably for parents who did not want to quit smoking their 'only safe haven', where they were not waiting for outsiders to educate them about smoking in their own house. Probably, this was also the reason why significantly more parents who exposed their children to SHS reported to find an internet program effective for parental education and prevention of SHS in children, compared to the parents of children without SHS exposure. Moreover, motivational interviewing at home and a group program in the neighbourhood were less mentioned as effective measures against SHS in these parents compared to the parents of children without SHS exposure, which may be for the same reason.

Current reports indicate that smoke-free legislation has led to an increase of total home smoking bans [27-30]. Scotland has achieved a 50\% reduction in the number of children exposed to SHS at home in the past 4 years (from $12 \%$ to $6 \%$ ) through governmental policy and national targeting of this issue using the www.rightoutside.org approach and a comprehensive media education campaign. However, it is unlikely that the increased rates of home smoking bans have limited the recruitment of eligible families for the PREPASE study, as the study was able to identify sufficient numbers of eligible families.

As mentioned previously, SHS exposure in children is particularly prevalent in the group of socially deprived families [2, 31-33]. But the findings of this current study imply that there is possibly also a hidden group of highly 
educated parents who expose their children to SHS and are not willing to quit either. The majority of the responders to our questionnaires reported to have middle-academic education and just a limited amount of parents reported to have a low education. Maybe the recruitment strategies did not reach this group effectively. Still, the questionnaires and study information were all provided in layman language. The questionnaire via schools was also shorter and computerized compared to the questionnaire via the communities and physicians, but this did not result in higher response rates. We identified a lack of knowledge of what constitutes SHS exposure. Many parents believe that they don't expose their child to SHS when they actually do. They believe that only smoking in one room, or smoking at the back door or with windows open mean their child isn't exposed. There clearly is a need for education by means of a media campaign.

\section{Comparison with other studies}

Literature concerning the recruitment of participants for similar studies is limited. Our results are comparable with the results of the REFRESH study in terms of recruitment [21]. This intervention study used 23 primary care practices in Scotland and recruited 68 mothers from 1,693 that were identified as smokers who had a child $<5$ yrs. of age living at home. Similar problems about the accuracy of primary care patient lists/details were mentioned in that study. Klosky et al. studied factors that influence non-participation in an intervention study to reduce SHS exposure in children diagnosed with cancer [34]. Barriers to participate included parental smoking status, parental gender, and child's health. Smoking parents were less likely to enrol in the study than non-smoking parents, according to the authors possibly due to guilt or the burden associated with changing their smoking behaviour.

\section{Strength and limitations}

The strength of this study is that valuable lessons have been learned from the recruitment process of the PREPASE study that provides insight into the problem of preventing SHS exposure in children. However, there are some limitations. First, we do not have additional information of all the physicians who were invited to recruit participants for the PREPASE study. Only 4 replied concerning possible participants, but that the rest did not reply does not necessarily mean that they did not try to recruit participants for the study. Likewise, the availability of characteristics of the non-participating parents were also limited and the actual number of parents exposed to one or more of the recruitment strategies are unknown. These limitations are mainly due to some ethical restrictions. Participation in the study was voluntary and parents could receive up to one reminder letter, as has been decided by the Medical Ethical Committee. More extensive analysis of the non-participants could have been performed by means of a qualitative study. But this was not possible in the time-span of the project due to the study delay resulting from the extensive recruitment process. Although the characteristics between the responders and non-responders (questionnaires $\mathrm{A}$ and $\mathrm{B}$ ) were equal, it is still probable that selective participation has occurred. Parents of children with SHS exposure could have been less motivated to participate with one of the recruitment strategies compared to parents of children without SHS. Furthermore, misclassification could also be a problem due to parental underreporting of their smoking behaviour. Before the distribution of questionnaires, we submitted all questionnaires and information leaflets to a group of parents/families $(n=10)$ with different levels of education. The suggestions and points for improvement identified by this group were used to improve the questionnaires and leaflets. However, we cannot exclude that the questionnaire was still not able to reach the target population adequately. The number of mothers/fathers exposing the child to SHS did differ between families participating and not participating in the trial. Finally, the observations in this study may not be generalizable to other countries.

\section{Implications}

The public health impact of successful interventions is dependent on its reach on population level. From this current study it is clear that reaching parents who expose their children to SHS is not effortless. However, if physicians were actively involved, the response of families was higher. Therefore, it is important that physicians are motivated to participate more actively in tackling the problem of SHS exposure in children and research on this topic. This study indicated a need for training on how physicians and health care professionals engage with smoking parents. The REFRESH study developed a How-To-Guide for practitioners. It is important that that policy makers and practitioners give priority to the protection of children from SHS exposure [21]. So far, the cooperation of physicians involved in care to children of this age to contribute to this project was limited. Additionally, the low participation of physicians in this study suggests that they may not address SHS exposure in children during consultations as frequently as required. Therefore, their practices regarding prevention of SHS exposure in children should be evaluated. More research should be done on how to overcome parental resistance due to for instance feelings of guilt/shame regarding SHS exposure in children, so that they can be reached effectively, not only for research but 
also for help for stopping SHS exposure in their children. Possibly, parents might be more comfortable with an electronic internet based program aimed at educating parents about SHS and how to stop SHS exposure in children.

\section{Conclusions}

The attempted recruitment strategies did not result in effective recruitment of participants for the PREPASE study, possibly due to the subject "SHS exposure in children" and other factors influencing parental participation. The presence of asthma in the family, respiratory symptoms in the children and even incentives did not increase parental motivation for participation. When the responsible physicians participated, the motivation of parents to participate increased. However, an important observation during the recruitment process of the study is the limited contribution of the physicians working in child care settings.

\section{Additional file}

Additional file 1: Questionnaires specifically developed for the PREPASE study. (DOCX $69 \mathrm{~kb}$ )

\section{Abbreviations}

95\% Cl: 95\% Confidence Interval; ADEM: Asthma DEtection and Monitoring; ISAAC: International Study of Asthma and Allergies in Childhood; MIKADO: Dutch acronym for Multifactorial intervention for children with asthma and overweight; MUMC: Maastricht University Medical Centre; OR: Odds Ratio; PREPASE: PREvention of PAssive Smoke Exposure: RCT: Randomized Controlled Trial; RNH: Dutch acronym for Registration Network of Family Physicians; SHS: Second-Hand Smoke; SPSS: Statistical Package for the Social Sciences; YHC: Youth Health Care

\section{Acknowledgements}

We thank: the civil affairs department of the communities of Heerlen, Maastricht and Sittard-Geleen; all physicians who participated in the study, $\mathrm{RNH}$, the Regional Public Health service, and the project teams of the MIKADO and ADEM study; the primary schools; research assistants and volunteers who helped with the recruitment processes; MEMIC Centrum for Data and Information Management Maastricht University; and, the Dutch Lung Foundation and ZonMw for funding the study. Also, all the students, families and friends who helped with the recruitment process.

\section{Funding}

The study was funded by the Dutch Lung Foundation (grant 3.4.08.047) and the Netherlands Organization for Health Research and Development (ZonMw) (grant VEMI 08-82305-97-12022).

\section{Availability of data and materials}

The datasets used and/or analysed during the current study are available from the corresponding author on reasonable request.

\section{Authors' contributions}

$\mathrm{SH}, \mathrm{CP}$ and ED designed the study. JM and FF advised on the design of the study and helped with the recruitment via RNH and YHC. SH wrote the first draft of the article. All authors participated in the interpretation of the findings, revised and approved of the final manuscript as submitted.

\section{Ethics approval and consent to participate}

The recruitment strategies were approved by the Medical Ethic Committee MUMC+. Questionnaire A was also used to analyse the association between
SHS and respiratory complaints in children in another manuscript [16]. Participants proved written consent information.

\section{Consent for publication}

Not applicable.

\section{Competing interests}

The authors declare that they have no competing interests.

\section{Publisher's Note}

Springer Nature remains neutral with regard to jurisdictional claims in published maps and institutional affiliations.

\section{Author details}

${ }^{1}$ Department of Paediatric Respiratory Medicine, Maastricht University Medical Centre (MUMC+) / CAPHRI School for Public Health and Primary Care, P.O. Box 616, 6200, MD, Maastricht, the Netherlands. ${ }^{2}$ Department of Family Medicine, MUMC+ / CAPHRI, P.O. Box 616, 6200, MD, Maastricht, the Netherlands. ${ }^{3}$ Department of Social Medicine, MUMC+ / CAPHRI, P.O. Box 616, 6200, MD, Maastricht, the Netherlands.

Received: 8 November 2016 Accepted: 4 January 2018

Published online: 31 January 2018

\section{References}

1. Wilson SR, Yamada EG, Sudhakar R, Roberto L, Mannino D, Mejia C, Huss N. A controlled trial of an environmental tobacco smoke reduction intervention in low-income children with asthma. Chest. 2001;120(5): 1709-22

2. Crone MR, Nagelhout GE, van den Burg I, RA HS. Passive smoking in young children in the Netherlands sharply decreased since 1996. Ned Tijdschr Geneeskd. 2010;154:A1658

3. Oberg M, Jaakkola MS, Woodward A, Peruga A, Pruss-Ustun A. Worldwide burden of disease from exposure to second-hand smoke: a retrospective analysis of data from 192 countries. Lancet. 2011:377(9760):139-46.

4. Passive smoking and children: A report by the Tobacco Advisory Group of the Royal college of Physicians. London: Royal College of Physicians; 2010. [http://www.rcplondon.ac.uk/sites/default/files/documents/passive-smokingand-children.pdf].

5. Murray RL, Britton J, Leonardi-Bee J. Second hand smoke exposure and the risk of invasive meningococcal disease in children: systematic review and meta-analysis. BMC Public Health. 2012;12:1062.

6. Burke H, Leonardi-Bee J, Hashim A, Pine-Abata H, Chen Y, Cook DG, Britton JR, McKeever TM. Prenatal and passive smoke exposure and incidence of asthma and wheeze: systematic review and meta-analysis. Pediatrics. 2012;129(4):735-44.

7. Difranza JR, Aligne CA, Weitzman M. Prenatal and postnatal environmental tobacco smoke exposure and children's health. Pediatrics. 2004;113(4 Suppl): 1007-15.

8. Rosen $\sqcup$, Noach MB, Winickoff JP, Hovell MF. Parental smoking cessation to protect young children: a systematic review and meta-analysis. Pediatrics. 2012;129(1):141-52.

9. Hutchinson SG, Mesters I, van Breukelen G, Muris JW, Feron FJ, Hammond SK, van Schayck CP, Dompeling E. A motivationa interviewing intervention to PREvent PAssive smoke exposure (PREPASE) in children with a high risk of asthma: design of a randomised controlled trial. BMC Public Health. 2013;13:177.

10. Willeboordse M, van de Kant KD, de Laat MN, van Schayck OC, Mulkens S, Dompeling E. Multifactorial intervention for children with asthma and overweight (Mikado): study design of a randomised controlled trial. BMC Public Health. 2013;13:494

11. van de Kant KD, Klaassen EM, Jobsis Q, Nijhuis AJ, van Schayck OC, Dompeling E. Early diagnosis of asthma in young children by using non-invasive biomarkers of airway inflammation and early lung function measurements: study protocol of a case-control study. BMC Public Health. 2009;9:210.

12. Hiemstra M, Ringlever L, Otten R, Jackson C, van Schayck OC, Engels RC. Efficacy of smoking prevention program 'Smoke-free Kids': study protocol of a randomized controlled trial. BMC Public Health. 2009;9:477.

13. Metsemakers JF, Hoppener P, Knottnerus JA, Kocken RJ, Limonard CB. Computerized health information in The Netherlands: a registration network of family practices. The British journal of general practice : the journal of the Royal College of General Practitioners. 1992;42(356):102-6. 
14. Irvine L, Crombie IK, Clark RA, Slane PW, Feyerabend C, Goodman KE, Cater J. Advising parents of asthmatic children on passive smoking: randomised controlled trial. BMJ. 1999;318(7196):1456-9.

15. Morgan WJ, Crain EF, Gruchalla RS, O'Connor GT, Kattan M, Evans R 3rd, Stout J, Malindzak G, Smartt E, Plaut M, et al. Results of a home-based environmental intervention among urban children with asthma. N Engl J Med. 2004;351(11):1068-80

16. Hutchinson SG, Penders J, Muris JWM, van Schayck CP, Dompeling E, Mesters I. Environmental tobacco smoke exposure and respiratory complaints in children aged 0-13 years: a cross-sectional study in SouthLimburg, The Netherlands. J Aller Ther. 2013;S11:002.

17. Kuiper S, Maas T, van Schayck CP, Muris JWM, Schönberger HJAM, Dompeling E, Gijsbers B, van Weel C, André Knottnerus J. The pg: the primary prevention of asthma in children study: design of a multifaceted prevention program. Pediatr Allergy Immunol. 2005;16(4):321-31.

18. Sureshkumar P, Caldwell P, Lowe A, Simpson JM, Williams G, Craig JC. Parental consent to participation in a randomised trial in children: associated child, family, and physician factors. Clin Trials. 2012;9(5):645-51.

19. van der Wouden JC, Blankenstein AH, Huibers MJ, van der Windt DA, Stalman WA, Verhagen AP. Survey among 78 studies showed that Lasagna's law holds in Dutch primary care research. J Clin Epidemiol. 2007;60(8):819-24.

20. Martin LA, Dilley KJ, Ariza AJ, Sullivan C, Seshadri R, Binns HJ. Pediatric practice research $\mathrm{G}$ : tobacco-related documentation in pediatric practice. Acad Pediatr. 2009;9(5):353-9.

21. Wilson I, Semple S, Mills LM, Ritchie D, Shaw A, O'Donnell R, Bonella P, Turner S, Amos A. REFRESH-reducing families' exposure to secondhand smoke in the home: a feasibility study. Tob Control. 2013;22(5):e8.

22. Victor JC, Brewster JM, Ferrence R, Ashley MJ, Cohen JE, Selby P. Tobaccorelated medical education and physician interventions with parents who smoke: survey of Canadian family physicians and pediatricians. Can Fam Physician. 2010;56(2):157-63.

23. Winickoff JP, McMillen RC, Carroll BC, Klein JD, Rigotti NA, Tanski SE, Weitzman M. Addressing parental smoking in pediatrics and family practice: a national survey of parents. Pediatrics. 2003;112(5):1146-51.

24. Hymowitz N. Pediatric residency training on tobacco: review and critique of the literature. J Natl Med Assoc. 2006;98(9):1489-97.

25. Browning KK, Ferketich AK, Salsberny PJ, Wewers ME. Socioeconomic disparity in provider-delivered assistance to quit smoking. Nicotine Tob Res. 2008;10(1):55-61.

26. Bain J, Weishaar H, Semple S, Duffy S, Hilton S. Vulnerable children, stigmatised smokers: the social construction of target audiences in media debates on policies regulating smoking in vehicles. Health (London). 2017 21(6):633-49. doi:https://doi.org/10.1177/13634593166332792016.

27. Borland R, Yong HH, Cummings KM, Hyland A, Anderson S, Fong GT. Determinants and consequences of smoke-free homes: findings from the international tobacco control (ITC) four country survey. Tob Control. 2006;15(Suppl 3):iii42-50.

28. Hyland A, Hassan LM, Higbee C, Boudreau C, Fong GT, Borland R, Cummings KM, Yan M, Thompson ME, Hastings $G$. The impact of smokefree legislation in Scotland: results from the Scottish ITC: Scotland/UK longitudinal surveys. Eur J Pub Health. 2009;19(2):198-205.

29. Fong GT, Hyland A, Borland R, Hammond D, Hastings G, McNeill A, Anderson $\mathrm{S}$, Cummings KM, Allwright $\mathrm{S}$, Mulcahy $\mathrm{M}$, et al. Reductions in tobacco smoke pollution and increases in support for smoke-free public places following the implementation of comprehensive smoke-free workplace legislation in the Republic of Ireland: findings from the ITC Ireland/UK survey. Tob Control. 2006;15(Suppl 3):iii51-8.

30. Fong GT, Craig LV, Guignard R, Nagelhout GE, Tait MK, Driezen P, Kennedy RD, Boudreau C, Wilquin JL, Deutsch A, et al. Evaluating the effectiveness of France's indoor smoke-free law 1 year and 5 years after implementation: findings from the ITC France survey. PLoS One. 2013;8(6):e66692.

31. Gartner CE, Hall WD. Is the socioeconomic gap in childhood exposure to secondhand smoke widening or narrowing? Tob Control. 2013;22(5):344-8. doi:https://doi.org/10.1136/tobaccocontrol-2011-050297.

32. Pisinger $\mathrm{C}$, Hammer-Helmich $\mathrm{L}$, Andreasen $\mathrm{AH}$, Jorgensen $\mathrm{T}$, Glumer $\mathrm{C}$. Social disparities in children's exposure to second hand smoke at home: a repeated cross-sectional survey. Environ Health. 2012;11:65.

33. Hiscock R, Bauld L, Amos A, Fidler JA, Munafo M. Socioeconomic status and smoking: a review. Ann N Y Acad Sci. 2012;1248:107-23.

34. Klosky JL, Tyc VL, Lawford J, Ashford J, Lensing S, Buscemi J. Predictors of non-participation in a randomized intervention trial to reduce environmental tobacco smoke (ETS) exposure in pediatric cancer patients. Pediatr Blood Cancer. 2009;52(5):644-9.

\section{Submit your next manuscript to BioMed Central and we will help you at every step:}

- We accept pre-submission inquiries

- Our selector tool helps you to find the most relevant journal

- We provide round the clock customer support

- Convenient online submission

- Thorough peer review

- Inclusion in PubMed and all major indexing services

- Maximum visibility for your research

Submit your manuscript at www.biomedcentral.com/submit
) Biomed Central 